\title{
Knowledge, Attitudes of Pregnant Women and Practices of Women Who Have Recently Given Birth on Contraception in the Immediate Postpartum Period at Principal Clinic of the Togolese Association of Family Well-Being Planning Center (ATBEF)
}

\author{
Bingo Kignomon M'bortche ${ }^{1 *}$, Francis Baramna-Bagou1, Baguilane Douaguibe ${ }^{2}$, \\ Kossi Edem Logbo-Akey3 ${ }^{3}$, Dédé Regina Ajavon ${ }^{3}$, Tina Ayoko Ketevi², Akila Bassowa ${ }^{4}$, \\ Abdoul-Samadou Aboubakari³, Koffi Akpadza²
}

${ }^{1}$ Principal Clinic of the Togolese Association of Family Well-Being Planning Center (ATBEF), Lomé, Togo

${ }^{2}$ Department of Gynecology-Obstetrics of the CHU Sylvanus Olympio, Lomé, Togo

${ }^{3}$ Department of Gynecology-Obstetrics of the CHU Kara, Kara, Togo

${ }^{4}$ Department of Gynecology-Obstetrics of the CHU Campus, Lomé, Togo

Email: *mbortche@yahoo.fr

How to cite this paper: M'bortche, B.K., Baramna-Bagou, F., Douaguibe, B., Logbo-Akey, K.E., Ajavon, D.R., Ketevi, T.A., Bassowa, A., Aboubakari, A.-S. and Akpadza, K. (2022) Knowledge, Attitudes of Pregnant Women and Practices of Women Who Have Recently Given Birth on Contraception in the Immediate Postpartum Period at Principal Clinic of the Togolese Association of Family Well-Being Planning Center (ATBEF). Open Journal of Obstetrics and Gynecolo$g y$, 12, 67-80.

https://doi.org/10.4236/ojog.2022.121007

Received: December 22, 2021

Accepted: January 23, 2022

Published: January 26, 2022

\begin{abstract}
Background: The use of modern contraceptive methods contributes to the reduction of maternal and neonatal mortality. The initiation of a contraceptive method in the immediate postpartum period is one of the strategies to avoid missing out on contraceptive opportunities. This strategy will reduce the unmet need for contraception which is still high in the country. Objective: To describe the knowledge and attitudes of pregnant women and the practices of women who have given birth about immediate postpartum contraception. Methodology: This was a cross-sectional and descriptive study conducted at the main clinic of ATBEF from 20th March to 20th October 2020. Our study included pregnant women whose gestational age was greater than or equal to 37 weeks of amenorrhea who came for prenatal consultation or for any other consultation and then gave birth in the center. Data collection was based on a survey form. Data analysis and entry was done with the Epi info 2000 version 6.04 software. The parameters studied were: socio-demographic characteristics, knowledge and attitudes of pregnant women about contraception in the immediate postpartum period, and contraceptive practices of the women who gave birth. Results: During the study period, 201 women were
\end{abstract}


Copyright (C) 2022 by author(s) and Scientific Research Publishing Inc. This work is licensed under the Creative Commons Attribution International License (CC BY 4.0).

http://creativecommons.org/licenses/by/4.0/ selected for the survey. The average age of the respondents was 26.2 years. They were nulliparous in $41.3 \%$ of cases. Our respondents had knowledge of modern contraceptive methods in $82.10 \%$ of cases. About $59.2 \%$ of the respondents had an unfavourable attitude towards the adoption of contraceptive methods in the immediate postpartum period. The main reason was adverse effects in $33.6 \%$. Of the 82 women who had a favourable attitude, 29 women had adopted a contraceptive method after delivery, which corresponds to a rate of use of $14.4 \%$ of the respondents. The main reason for non-adoption of a contraceptive method after childbirth for those who had a favourable attitude was the opposition of the husband in 34\%. Conclusion: Couple counselling during prenatal and postnatal care and intensified awareness raising on planning and ideal spacing of pregnancies for health will increase the number of contraceptive users in the immediate postpartum period.

\section{Keywords}

Contraception, Postpartum, Pregnant Women, Delivered Women, Lomé

\section{Introduction}

Postpartum contraception is the use of modern or natural contraceptive methods to prevent unplanned or closely spaced pregnancies during the first 12 months after delivery [1]. The time of return to fertility after childbirth is on average 45 days, although ovulation can occur as early as day 20, especially if there is no breastfeeding [2]. It is necessary to start a contraceptive method before this period to avoid unplanned pregnancies and close pregnancies since about 5.5\% of voluntary pregnancy terminations occur in the six months following childbirth each year in the world due to lack of use of contraceptive methods [3].

In Togo, modern contraceptive prevalence is $21.4 \%$ and unmet need is $34 \%$ [4]. The low contraceptive prevalence is thought to be due to missed opportunities to get women to initiate the use of contraceptive methods. The immediate postpartum period is therefore a good time to initiate contraceptive use since every sexually active woman should avoid pregnancy for at least two years.

We therefore initiated this study to:

- assess pregnant women's knowledge of contraception in the immediate postpartum period;

- describe pregnant women's attitudes towards immediate postpartum contraception;

- describe the reasons for not using contraception in the immediate postpartum period.

\section{Methodology}

This was a cross-sectional study conducted in the maternity ward of the main clinic of the ATBEF from 20 March to 20 October 2020, i.e. a duration of six months. 
Our study included

- pregnant women or parturients whose gestational age was greater than or equal to 37 weeks of amenorrhea on the basis of the date of the last menstrual period or on the basis of the ultrasound of the first trimester;

- pregnant women or parturients seen during the study period for prenatal consultation, early labour or any other problem

- pregnant women or women in labour who have received family planning counselling;

- women who gave birth during the study period.

Data collection was carried out using a survey sheet developed and tested for this purpose. Data collection was done in two stages.

First stage: information was collected from pregnant women who met the inclusion criteria at the end of the consultations. The collection procedure consisted of interviewing the women and filling in the survey sheet. If necessary, the health booklet (prenatal consultation booklet) was consulted to complete some information. Pregnant women were recruited as they came to the clinic.

The second step was to collect information from these women after delivery during the two days postpartum. This information was collected from the records of the women who had given birth, from family planning cards and from the women's health diaries. If necessary, some questions were asked to these women.

The data was collated manually. Data entry and analysis were done with Epi info 2000 version 6.04, Microsoft Excel 2013.

The parameters studied were: socio-demographic characteristics (age, marital status, level of education, occupation), pregnant women's knowledge of immediate postpartum contraception, pregnant women's attitudes towards immediate postpartum contraception, reasons for not using the method after delivery.

The respondents were recruited anonymously. Moreover, the women included in the study were recruited only after their prior consent.

The immediate postpartum period was considered to be the period from delivery to 48 hours postpartum. This period included the post-placental period, i.e. ten minutes after delivery, the per-section period, i.e. during the caesarean section, and the immediate postpartum period, i.e. the period up to 48 hours postpartum.

In this study, in order to assess the knowledge of the women surveyed about contraceptive methods, the survey sheet had specified three relevant information about the method: route of administration, duration of action and two adverse effects. Thus:

- Knowledge about the method was good if the respondent gave the three relevant information

- Knowledge of the method was average if the respondent gave two of the three relevant information

- Knowledge about the method was poor if the respondent gave only one relevant piece of information or could not give any relevant information. 


\section{Results}

\subsection{Number of Respondents}

During the study period, 267 pregnant women meeting our selection criteria were surveyed. Of these, 201 had given birth, i.e. $75.3 \%$ of cases. The main results were related to the 201 women.

\subsection{Socio-Demographic Characteristics}

The average age of the respondents was 26.2 years, with extremes of 15 and 40 years. Most of the respondents were craftswomen (hairdresser, seamstress) with a percentage of $30.4 \%$ (Table 1 ).

Table 1. Distribution of respondents according to their socio-demographic characteristics.

\begin{tabular}{|c|c|c|}
\hline & Number & Percent \\
\hline \multicolumn{3}{|l|}{ Age in year $(n=201)$} \\
\hline$[15-19[$ & 43 & 21.4 \\
\hline$[19-35[$ & 144 & 71.7 \\
\hline$[35-40]$ & 14 & 6.9 \\
\hline \multicolumn{3}{|l|}{ Occupation $(n=201)$} \\
\hline Artisan $^{*}$ & 61 & 30.4 \\
\hline Merchant/Reseller & 42 & 20.9 \\
\hline Housewife & 35 & 17.4 \\
\hline Office worker & 26 & 12.9 \\
\hline Student & 24 & 11.9 \\
\hline Teacher & 13 & 6.5 \\
\hline \multicolumn{3}{|c|}{ Level of education $(n=201)$} \\
\hline not in school & 23 & 11.4 \\
\hline primary level & 67 & 33.3 \\
\hline secondary level & 67 & 33.3 \\
\hline tertiary leve & 44 & 21.9 \\
\hline \multicolumn{3}{|l|}{ Religion ( $n=201$ ) } \\
\hline Catholic & 89 & 44 \\
\hline Protestant & 57 & 28 \\
\hline Muslim & 38 & 19 \\
\hline Animist & 17 & 8 \\
\hline \multicolumn{3}{|c|}{ Marital status $(n=201)$} \\
\hline married & 136 & 67.7 \\
\hline single & 64 & 31.8 \\
\hline divorced & 1 & 0.50 \\
\hline
\end{tabular}




\subsection{Number of Children}

In our study, $41.3 \%$ of the respondents were nulliparous (Table 2 ).

\subsection{Knowledge about Postpartum Contraception}

\subsubsection{Time to Resume Sexual Activity and Next Pregnancy}

In our study, $54.2 \%$ of the respondents stated that the time to resume sexual activity was 3 to 6 months after delivery. In $31.3 \%$ of cases, the time between delivery and a new pregnancy was 3 years (Table 3 ).

Table 2. Distribution of respondents according to parity and number of children.

\begin{tabular}{ccc}
\hline & Number & Percent \\
\hline Parity $(\mathbf{n}=\mathbf{2 0 1})$ & & \\
\hline nulliparous & 83 & 41.3 \\
primiparous & 63 & 31.3 \\
paucipare & 48 & 23.9 \\
multiparous & 7 & 3.5 \\
\hline Number of children $(\mathbf{n}=201)$ & & 41.3 \\
\hline None & 83 & 31.3 \\
one & 63 & 24.9 \\
two to three & 50 & 2.5 \\
four or more & 5 & \\
\hline
\end{tabular}

Table 3. Distribution of respondents according to the period between childbirth and a new pregnancy.

\begin{tabular}{|c|c|c|}
\hline & Number & Percent \\
\hline \multicolumn{3}{|c|}{ Period between childbirth and resumption of sexual intercourse $(n=201)$} \\
\hline 1 week to 3 months & 14 & 7 \\
\hline 3 to 6 months & 109 & 54.2 \\
\hline $6-12$ months & 19 & 9.5 \\
\hline $1-2$ years & 22 & 10.9 \\
\hline After 2 years & 4 & 2 \\
\hline Don't know & 33 & 16.4 \\
\hline \multicolumn{3}{|c|}{ Time between childbirth and re-pregnancy $(n=201)$} \\
\hline 12 months & 22 & 10.9 \\
\hline 18 months & 14 & 7 \\
\hline 2 years & 51 & 25.4 \\
\hline 3 years & 63 & 31.3 \\
\hline More than 3 years & 35 & 17.4 \\
\hline Don't know & 16 & 8 \\
\hline
\end{tabular}




\subsubsection{Knowledge of Contraceptive Methods in the Immediate Postpartum Period}

Among the respondents, $82.1 \%$ had declared that they had general knowledge about contraceptive methods in the immediate post-partum period. They had obtained this knowledge from family and friends (46.1\%), the mass media (30.9\%) and medical personnel (23\%). The pill was the most widely known contraceptive method (Table 4).

\subsubsection{Assessment of Knowledge of the Various Contraceptive Methods} The level of knowledge of respondents was good in $48.1 \%$ for pills and $57.8 \%$ for injectable contraceptives (Table 5).

\subsection{Attitudes of Respondents}

\subsubsection{Desired Method to Adopt after Delivery}

Among the respondents, $40.8 \%$ had opted to use a contraceptive method in the immediate postpartum period. Of these, $32.9 \%$ had wanted to use the progestin-only pill, and $29.3 \%$ had wanted to use the contraceptive implant after giving birth (Table 6).

\subsubsection{Reason for Not Using Contraception}

Among the respondents, 59.2\% had not wanted to initiate a contraceptive method in the immediate post-partum period. The main reasons given were: undesirable effects of contraceptive methods (36.4\%), religious constraint (26.4\%), desire for other children (15.1\%), difficulties in becoming pregnant again (12.6\%), rumours $(14.3 \%)$.

\subsection{Contraceptive Use by Postpartum Women}

Of the 201 respondents who had given birth, 29 had adopted a contraceptive method, a rate of $14.4 \%$. During pregnancy, 82 respondents said they wanted to use a contraceptive method in the immediate postpartum period. Of these, 29 respondents had initiated the contraceptive method.

Table 4. Distribution of respondents according to contraceptive methods available in the immediate post-partum period.

\begin{tabular}{ccc}
\hline Pills & Number & Percent \\
Condoms & 156 & 77.6 \\
Implant & 103 & 51.2 \\
Injectable contraceptives & 88 & 43.8 \\
Copper intrauterine device & 64 & 31.8 \\
MAMA method & 47 & 23.4 \\
Tubal ligation & 34 & 16.9 \\
& 6 & 2.9
\end{tabular}


Table 5. Distribution of respondents according to their level of knowledge by method.

\begin{tabular}{|c|c|c|}
\hline & Number & Percent \\
\hline \multicolumn{3}{|c|}{ Pills $(n=156)$} \\
\hline Good & 75 & 48.1 \\
\hline average & 40 & 25.6 \\
\hline poor & 41 & 26.3 \\
\hline \multicolumn{3}{|c|}{ Implant $(\mathrm{n}=88)$} \\
\hline good & 41 & 46.6 \\
\hline average & 29 & 32.9 \\
\hline poor & 18 & 20.5 \\
\hline \multicolumn{3}{|c|}{ Copper intrauterine device $(n=47)$} \\
\hline good & 20 & 42.6 \\
\hline average & 18 & 38.3 \\
\hline poor & 9 & 19.1 \\
\hline \multicolumn{3}{|c|}{ Condoms $(n=103)$} \\
\hline good & 70 & 68 \\
\hline average & 25 & 24.3 \\
\hline poor & 8 & 7.7 \\
\hline \multicolumn{3}{|c|}{ MAMA method $(\mathrm{n}=34)$} \\
\hline good & 15 & 50 \\
\hline average & 10 & 33.3 \\
\hline poor & 5 & 16.7 \\
\hline \multicolumn{3}{|c|}{ Injectable contraceptives $(n=64)$} \\
\hline good & 37 & 57.8 \\
\hline average & 18 & 28.1 \\
\hline poor & 9 & 14.1 \\
\hline \multicolumn{3}{|c|}{ Tubal ligation $(n=6)$} \\
\hline good & 3 & 50 \\
\hline average & 1 & 16.7 \\
\hline poor & 2 & 33.3 \\
\hline
\end{tabular}

Table 6. Distribution of respondents according to the methods chosen.

\begin{tabular}{ccc}
\hline & Number & Percent \\
\hline Progestin-only pills & 27 & 32.9 \\
Implant & 24 & 29.3 \\
Condoms & 13 & 15.9 \\
Copper intrauterine device & 10 & 12.2 \\
Injectable contraceptive & 4 & 8.5 \\
Tubal ligation & 1 & 1.2 \\
Total & $\mathbf{8 2}$ & 100 \\
\hline
\end{tabular}


The methods adopted were jadelle* implants in 12 cases (6\%), the intrauterine device in 9 cases (4.5\%), progestin-only pills in 7 cases (3.5\%) and tubal ligation in 1 case (0.5).

The time of administration of the method was post-placental in 6 cases, immediate postpartum in 20 cases, and per-section in 3 cases.

The main reasons given by those who no longer agreed to use the method were: opposition from the spouse (34\%), rumours about the chosen method (24.5\%), opposition from the in-laws (7.6\%), partner travelling $(24.5 \%)$ and contraindication of the chosen method (9.4\%).

\section{Discussion}

\subsection{Surveyed Women's Knowledge of Contraceptive Methods in the Immediate Postpartum Period}

In our study, $82.10 \%$ of our respondents had knowledge of contraceptive methods in the immediate postpartum period. This rate is higher than that obtained by Julie Munery, who found in her study that $75 \%$ of respondents had knowledge of contraceptive methods [5]. This high rate can be explained by the counselling sessions that these women had during prenatal care and by the many awareness-raising activities in the country.

\subsection{Respondents' Attitudes towards Contraception}

Among the respondents, 59.2\% were not in favour of adopting a contraceptive method in the immediate postpartum period. The main reasons given were undesirable effects in $33.6 \%$, the husband's opinion in $24.4 \%$, and the desire for other children in $15.1 \%$.

In fact, the side effects of contraceptive methods are the most common reasons for not using contraception, as noted in the study. The side effects of contraceptive methods are variable and depend in part on the user. Sometimes these side effects could be amplified by women who have had to use a contraceptive method, especially when these side effects are not given to them during counselling before the initiation of the contraceptive method.

The husband's opinion on the adoption of a contraceptive method is important in our society where the woman does not always have decision-making power in general and family welfare in particular. Involving men in maternity services will increase the number of women using contraceptive methods in the immediate post-partum period.

Some rumours about the use of contraceptive methods in the postpartum period leading to difficulties in conceiving and the abandonment of the method are still relayed in the general population. Some respondents believe that it is possible to have close deliveries without worrying about their health, since in the study $10.95 \%$ of the respondents said that the reproductive interval was 12 months. The short interval between pregnancies is associated with a significantly higher risk of prematurity [6]. Well-conducted counselling will therefore dispel these 
rumours, giving true information about the qualities of a contraceptive method and presenting the benefits of ideal pregnancy planning and spacing for health (IPPS).

Forty-eight percent of the respondents were in favour of using methods in the postpartum period. Of these, $41.5 \%$ wanted to use long-acting methods (Jadelle* implant and copper IUD*). This result could be explained by the fact that the women understood the importance of the ideal spacing of pregnancies for their health, since $74.1 \%$ of cases said that the duration of the inter-reproductive space was at least 2 years.

\subsection{Immediate Postpartum Contraceptive Practices of Respondents}

Of the 201 respondents who had given birth, 29 had adopted a modern contraceptive method, a rate of $14.4 \%$. The methods adopted were jadelle implants in 12 cases $(6 \%)$, the intrauterine device in 9 cases (4.5\%), progestin-only pills in 7 cases (3.5\%) and tubal ligation in 1 case (0.5\%). Any contraceptive method prescribed to a breastfeeding woman must not only be adapted to her physiological state after childbirth and to the health of her newborn, but also correspond to her expectations [7] [8].

This rate found in our study could be explained by the understanding of the PEIGS by these respondents since $27.4 \%$ of them had at least two children and could appreciate the benefits of contraception on the health of the woman, that of the child as well as the well-being of the family. Most studies state that the average return to labour occurs six weeks after delivery. However, ovulation can occur as early as day 25, especially if there is no breastfeeding. Therefore, postpartum contraception is a priority in the postpartum period. Doctors and midwives should endeavour to provide up-to-date information on the various contraceptive strategies, to detect any contraindications and to prescribe effective contraception to each woman who wishes to use it before leaving the maternity hospital [9] [10] [11].

\subsection{Reasons for Not Using the Method after Delivery}

During the pregnancy, 82 respondents had wanted to use a contraceptive method in the immediate postpartum period. Of these, $64.6 \%$ had not adopted a contraceptive method after delivery. The main reasons given were the opposition of the spouse in $34 \%$, the husband travelling in $24.5 \%$, the contraindication of the method in $9.4 \%$, and the opposition of the family-in-law in $7.6 \%$.

The opposition of the spouse in the adoption of a method could be explained by the pro-natalist attitude of men in our society and by a fear concerning a rumour of reduced libido in some users of hormonal methods. Counselling of the couple during prenatal follow-up will explain the quality of hormonal methods, their mechanism of action and the advantages of PEIGS. In our study $67.7 \%$ of the respondents were married and living together with their spouses. This means 
that women whose husbands had travelled during pregnancy or after delivery would not need contraception immediately after delivery. It is important to remind these women of the use of contraceptive methods as needed to avoid surprise close pregnancies once the husbands return periodically or permanently when the child is not yet at least 2 years old. In our study, although the women were willing to use a contraceptive method in the postpartum period, their health status did not allow them to do so. Indeed, chorioamniotitis, rupture of membranes of more than 18 hours, postpartum haemorrhage and significant perineal lesions are universally accepted contraindications to the insertion of the copper intrauterine device in the immediate postpartum. The opposition of the in-laws found in our study would be related to the place of mothers-in-law in the household and also to the fact that the woman negotiated the use of the contraceptive method with her husband in the presence of the mother-in-law. The introduction of couple counselling after childbirth would avoid the negotiation that women would be used to doing with their husbands in the presence of their mothers-in-law.

\subsection{Limitations of the Study}

Our study encountered some difficulties, firstly the unavailability of some pregnant women at the time of the survey, and secondly the data from the present study are declarations made by the pregnant women, which leads to imprecision and it is likely that not all of this information is accurate. This is a limitation of the study.

\section{Conclusion}

The immediate postpartum period is a good time to initiate the use of a modern contraceptive method. This will reduce unmet need for family planning and contribute to the reduction of maternal and neonatal mortality. Couple counselling during prenatal and postnatal care and increased awareness of planning and ideal spacing of pregnancies for health will increase the number of contraceptive users in the immediate postpartum period.

\section{Conflicts of Interest}

The authors declare no conflicts of interest regarding the publication of this paper.

\section{References}

[1] Organisation Mondial de la Santé (2014) Stratégie de programmation pour la Planification Familiale du Postpartum. OMS, USAID, MCHIP.

[2] Jackson, E. and Glasier, A. (2011) Return of Ovulation and Menses in Postpartum Nonlactating Women: A Systematic Review. Obstetrics \& Gynecology, 117, 657-662. https://doi.org/10.1097/AOG.0b013e31820ce18c

[3] Blangis, F., Lopes, P., Branger, B., Garnier, P., Philippe, H.-J. and Ploteau, S. (2013) 
La contraception du post-partum: à propos de 600 patientes dont 129 revues à la consultation post-natale. Gynécologie Obstétrique et Fertilité, 41, 499-504. https://doi.org/10.1016/j.gyobfe.2013.07.017

[4] Institut National de la Statistique et des Etudes Economiques et Démographiques (INSEED) (2018) MICS6 TOGO, 2017, Rapport final. Lomé, Togo.

[5] Munery, J. (2016) La contraception du post-partum: Étude descriptive des connaissances des accouchées du 19 octobre au 26 novembre 2015 d'une maternité d'auvergne de type trois sur leur contraception du post-partum. Gynécologie et obstétrique. 〈dumas-01566880).

[6] Dedecker, F., Graesslin, O., Ceccaldi, P.-F., Baudelot, E., Montilla, F., Derniaux, E., et al. (2008) Grossesses rapprochées : facteurs de risques et conséquences périnatales. Journal de Gynécologie Obstétrique et Biologie de la Reproduction, 35, 28-34. https://doi.org/10.1016/S0368-2315(06)76369-4

[7] Serfaty, D. (2015) Contraception des femmes allaitantes: Place des spermicides. Journal de Gynécologie Obstétrique et Biologie de la Reproduction, 44, 18-27. https://doi.org/10.1016/j.jgyn.2014.07.001

[8] Vandenbroucke, L., Lavoué, V., Voltzenlogel, M.-C., Le Guellec, M., Lassel, L., Isly, H., et al. (2013) Facteurs de risques et conséquences périnatales des grossesses rapprochées : Étude cas-témoin rétrospective. Journal de Gynécologie Obstétrique et Biologie de la Reproduction, 42, 166-173. https://doi.org/10.1016/j.jgyn.2012.09.010

[9] Fanello, S., Parat-Pateu, V., Dagorne, C., Hitoto, H., Collet, J., Routiot, T., et al. (2007) La contraception du post-partum: les recommandations médicales, le point de vue des femmes. Journal de Gynécologie Obstétrique et Biologie de la Reproduction, 36, 369-374. https://doi.org/10.1016/j.jgyn.2006.12.002

[10] Robin, G., Massart, P., Graizeau, F. and du Masgenet, B.G. (2010) La contraception du postpartum : État des connaissances. La Revue Sage-Femme, 9, 31-43. https://doi.org/10.1016/j.sagf.2010.01.001

[11] Colson, M.-H. (2014) Sexualité féminine et étapes de la parentalité. Gynécologie Obstétrique \& Fertilité, 42, 714-720. https://doi.org/10.1016/j.gyobfe.2014.09.001 


\section{Survey Sheet}

1. Socio-demographic characteristics

- Age in years:

- Education level:

- Your marital status: $\square$ Married $\square$ Single

- Your profession:

- Your religion:

2. Background

- Specific personal history:

- Obstetrical history: Gestity:..........Parity:

- Number of living children:

- Number of children desired to have:.

- Previous method used: none $\square$, implant $\square$, intrauterine device $\square$,

- depo provera* $\square$, pills $\square$, other $\square$ if other, specify

3. Reasons for visit

- For prenatal consultation

- For early labour

- For another problem $\square$

- If other problem, specify.

4. Term of pregnancy

Term of pregnancy in weeks of amenorrhea:

5. Respondents' knowledge of contraception in the immediate postpartum period

5.1. After delivery how long should the couple wait to resume sexual intercourse?

- Less than 3 months

- 3 - 6 months

- 6 - 12 months

- 1 - 2 years $\square$

- Don't know

- Other $\square$ : If other, specify:

5.2. What do you think is the interval in months or years between the new pregnancy and the previous child?

- 12 months

- 18 months

- 2 years

- 3 years

- More than 3 years

- Don't know

5.3. After giving birth do you know that contraception is done before going home?

Yes ( ) No ( )

5.4. Who gave you information about contraception that can be used fol- 
lowing childbirth? (If yes for question 2)

- A medical staff $\square$

- Family and friends

- Friends

- Mass media

- Social networks

- Other $\square$. If other, specify.

5.5. Which immediate postpartum contraceptive method do you know?

- Condoms $\square$

- Pills

- Implant $\square$

- Intramuscular progesterone injections

- Intrauterine device (IUD)

- LAM methods

- No contraceptive method

5.6. What do you know about these different methods

Knowledge about the pills

- can prevent pregnancy when taken

- you take it every day $\square$

- side effects like headache, amenorrhea, weight gain, spotting $\square$

- Don't know

Knowledge about condoms.

- Prevents STIs and pregnancy

- It is worn when the penis is erect $\square$

- No side effects $\square$

- Don't know $\square$

Knowledge about implants.

- It can be used in the immediate post partum period

- Its duration of action is 3 years or 5 years

- Side effects: amenorrhea, weight gain, headaches

- Don't know

Knowledge about the LAM method (breastfeeding and amenorrhea method).

- is used up to 6 months after delivery

- the mother must be in postpartum amenorrhoea

- Child must be exclusively breastfed (8 feeds per day)

- Don't know

Knowledge about the intrauterine device

- It can be used in the immediate postpartum

- Its duration of action is 12 years

- Side effects: heavy menstrual flow, bleeding outside the period, pelvic cramps

- Don’t know $\square$ 
Knowledge about injectable contraceptives (Depo provera*).

- It can be used in the post partum period from six weeks

- Its duration of action is 3 months

- side effects: amenorrhea, weight gain, headache

- Don't know

1. Attitudes after delivery

After your delivery do you intend to use a method to delay or avoid getting pregnant?

- No $\square$ Yes $\square$

- If yes which one:

If no what is the main reason you do not intend to use a method after giving birth?

- Desire for children

- Difficulty getting pregnant

- Contrary to religion

- No answer

- Don't know $\square$

- Difficulty in obtaining (accessibility)

- Side effects

- Other $\square$, If other specify

2. Practice after delivery

Method adopted in the postpartum period

- Condoms $\square$

- Pills

- Implant

- Intramuscular progesterone injections

- Intrauterine device (IUD)

- LAM methods

- No contraception

When the method is adopted

- Post placental $\square$

- Per caesarean

- Immediate post partum

Reasons for not adopting the method

- opposition from spouse

- rumours about the chosen method

- opposition from in-laws

- travelling partner

- contraindication of the chosen method $\square$

- Did not prefer to use method in post partum

- Other $\square$, if other specify. 